\title{
Mal-estar na CUltura: CORPO E animalidade em Kafka, Freud e Coetzee
}

Márcio Seligmann-Silva (IEL, UNICAMP)

\section{Ato}

Investigações de um símio ou Nós animais em Kafka

Caríssimos colegas da academia, não podem imaginar como fiquei tocado e emocionado com este convite: escrever sobre os animais na obra de meu amigo Franz Kafka. Sim, meu amigo. Muitos de vocês não o sabem, mas o conheci pouco depois de ele ter publicado - para meu furor: sem a minha permissão - o relatório, que logo se tornou famoso. Refiro-me, é claro, ao Ein Bericht für eine Akademie (Um relatório para uma academia). Naquela ocasião eu era ainda jovem e não havia entrado na academia, onde se aprende toda sorte de manobras e de trapaças. Então eu era inocente e puro. Mas fico especialmente feliz com esse convite, porque escrever sobre esse tema permite-me não só voltar a ler as páginas já bem amareladas da obra única daquele (apesar de tudo) grande escritor de Praga - aliás: que linda cidade! - como também me voltar para colegas que moram do outro lado do Equador, em um país tropical, como aquele que habitei até os cinco anos de idade. Como sabem, desde aquela idade moro em Hamburgo, encantadora cidade portuária alemã. Mas chega de introduçôes! O espaço é pequeno e estou com quase cem anos, dependo de minha secretária, Frau Bündschen, que precisa ir para casa cuidar de seu filho recém-nascido.

Comecemos pelo início: por que Kafka abriu um espaço tão privilegiado para animais em seus textos? Para mim isto é um sinal de inteligência! Assim ele pôde pensar melhor no próprio animal-humano. Sinceramente, como macaco, primo de vocês, posso dizer que o Sr. Kafka deve ter sido um dos que melhor soube mergulhar nesse homem do século XX, ou seja, alguém que não se sente em casa nem no próprio corpo. De animais mesmo ele não entendia quase nada. Ele gostou de meu relatório porque lá apresento como o ser-humano está a um passo do ser-animal. Eu atravessei a galope o processo evolutivo, que vocês levaram centenas de milhares de anos para trilhar. Como vocês, também eu me tor- 
nei humanizado pecando, ou seja, fazendo sujeira e rindo: cuspindo, bebendo e fumando! Comecei pelo schnaps e cheguei ao vinho tinto. Adoro as uvas suaves das montanhas da região de Chirouble. (Já sabem com o que me presentear!) Eu fui reconhecido mesmo como humano quando soltei um "alô", após virar uma garrafa de eau de vie. Daí em diante foi tudo uma questão de imitação. Eu, como todo bom macaco, sou um excelente imitador. De macaco a animal-humanizado e daí a professor foram poucos passos. Tudo é uma questão de saber imitar bem, como já o sabia o bom Aristóteles. Kafka ficou fascinado com essa ideia. Talvez isto tenha a ver com a situação dos judeus na Europa, que em pouco tempo foram da marginalidade e do shtetl (as aldeias judaicas do leste europeu) para as grandes Universidades, mas isto é só uma hipótese divertida. Não se esqueçam que ele era um admirador de Darwin - o único cientista que realmente respeito - e mesmo Freud (que também admirava aquele cientista inglês), apesar de ter sido ironizado por Kafka, no fundo era admirado por ele também. Afinal, o que Kafka vê como sendo o meu processo de humanização, Freud também o descreve em seus escritos "Totem e tabu" (que ele pode ter lido) e em "O mal-estar na cultura", de 1930. (Sim, "O mal-estar na cultura", e não "na civilização". Freud não era Rousseau, aquele filósofo suíço que, como escreveu Voltaire, gostaria de ter voltado a andar de quatro e retornado à floresta. Rousseau era crítico da civilização, Freud foi mais fundo e viu que o homem está condenado a morar no mal-estar, unbehagen, onde quer que ele viva, ou seja, está condenado a sentir-se desabrigado. Também eu me sinto assim desde que bradei aquele fatídico "alô".)

No mesmo volume em que Kafka publicou o meu texto, lemos ainda outros que me parecem importantes para minha temática. Um dele é o "Chacais e árabes". Trata-se de uma pequena peça sobre a relação desses lobos do deserto com os árabes. O narrador é um "europeu do norte". Mas o interessante é que o protagonista é o líder dos chacais. Aqui vemos um dos toques da genialidade de Kafka. É preciso recordar que ele construiu boa parte de sua obra em meio a seus diários (que eram, na verdade, "noitários": textos escritos de noite que continham também muitos sonhos). Sua obra nascia como parte de sua vida. Ele construía personagens em seus textos de tal modo que os leitores têm uma forte tendência a identificá-los com o seu autor, ou seja, com Kafka. Ele soube como poucos com a sua pena introjetar e disseminar o gesto auto- 
-bio-gráfico, central na literatura desde então. Assim, eu mesmo já fui identificado com o escritor de Praga. Mas no caso específico dessa narrativa desses chacais reconheço que a tentação é grande de considerá-los uma tribo de judeus que há séculos luta com os árabes. Trata-se de uma luta que é descrita como nascida do sangue e que terminará em sangue. "Precisamos de paz com os árabes", clama o lobo. Ele sonha com um deserto sem aqueles hábitos sujos e bárbaros dos árabes; sonha com mortes limpas, rituais e sem sangue dos animais que eles precisam comer. Corroborando com essa leitura judaizante, é importante lembrar que Kafka publicou o meu texto e esse sobre os chacais na importante revista editada por Martin Buber, Der Jude, em 1917. Mas, para mim, o decisivo não é o olhar étnico, mas o olhar sobre o animal-humano que Kafka abre nesse texto. $\mathrm{O}$ animal é o limpo, os homens são os sujos: Kafka brinca de amarelinha na estrada tortuosa da "evolução" dita humana, ou ainda: ele joga lego com as peças da Criação.

Outro ensaio do mesmo volume Um médico rural (publicado, aliás, em 1920) trata de uma pequena cidade que é invadida por "nômades do norte". Nesse pequeno texto, intitulado "Uma folha antiga", novamente assistimos à operação de animalizar os homens, ou de despir esses animais envergonhados de sua tênue roupagem humana. Esses bárbaros comem carne crua - assim como os seus cavalos. Eles muitas vezes compartilham o mesmo pedaço de carne que devoram juntos. E se uma vaca viva lhes é lançada, bárbaros e cavalos a dilaceram loucamente com seus dentes afiados, de um modo que só Eurípides havia antes descrito em suas Bacas, referindo-se ao frenesi das tebanas enfeitiçadas por Dioniso. Essa narrativa kafkiana conta a história da dissolução da cidade realizada pela inoculação dessa invasão "animal" (aliás, bem dionisíaca também). Mas ela é mais do que isso. Ela apresenta o rei impotente no palácio imperial como uma metáfora da crise no poder soberano que, por sua vez, para existir, precisa domar a "vida natural" (zoe), a "vida nua”, como escreveu outro famoso contemporâneo de Kafka, Walter Benjamin. Ao tratar da vida animal, Kafka toca na crise da soberania e da nossa autoimagem. Essas duas crises se lhe aparecem como paralelas. Ele mostra o animal em nós, como Freud e, antes dele, Darwin o fizera. Ele mostra um poder amorfo, teoricamente o monopolizador da violência, que tenta gerir essa vida nua que lhe escapa (à qual Penteu e Cadmo, avô de Dioniso, também sucumbiram por não saberem venerar e sacrificar aos deuses). 
Mas Kafka trabalha com polaridades para as desconstruir. Esse é o charme de sua narrativa. Isto fica claro novamente no pequeno texto "O novo advogado", que abre o mesmo volume e traz Bucéfalo, o cavalo de Alexandre o Grande, como um eminente advogado. Ele estuda e representa a lei. $\mathrm{O}$ animal, que foi recalcado em nós e sobre cujo sacrifício inscrevemos a cultura, é quem porta a insígnia de delegado e é representante de nosso super-eu. A literatura é essa "pesquisa" sobre o humano que se dá via mergulho no nosso ser animal.

Assim também se passa no maravilhoso texto do espólio que foi publicado pelo nosso amigo Max Brod, justamente com o título "Investigações de um cão". Esse, de todos os textos com animais de Kafka, é aquele no qual mais sentimos a busca de um ponto de vista animal (falo isso com conhecimento de causa, apesar de minha infância animal se perder nas penumbras profundas de minha alma). Novamente a tentação de ler esse texto como um ensaio sobre a condição do judeu sem pátria, lugar e corpo é grande. A narrativa em primeira pessoa é prodigiosa: sentimo-nos sobre quatro patas e lendo esse texto, se não me contenho, retomo o antigo gesto de coçar minhas orelhas com meus pés. De resto esse cão investigador passa por um rigoroso jejum e recebe a comida de modo forçado pela sua boca. Impossível não pensar no anoréxico Kafka e sua atração por figuras que se desfazem destruídas pela inanição, como o seu artista da fome. Mas vamos deixar essa tentação de lado. Esse animal, que está em meio a sua pesquisa e a vê como uma espécie de tábua de salvação para sua crise de vida, estuda justamente a questão da fome: protofenômeno de nossa (e com isso incluo a nós todos animais) existência. Esse cão é o primeiro grande pesquisador moderno da vida nua, e com isso se mostra um precursor de Benjamin e de St. Agamben. Como o próprio narrador canino kafkiano escreve: "Todo o conhecimento, o conjunto de todas as perguntas e de todas as respostas, está contido nos cães." Essa figura canina tem uma imagem em sua memória animal que a assombra. Trata-se daquilo que Freud denominou de Urszene, protocena, um espetáculo traumatizante que tem grande intensidade e uma forte carga sexual. Essa cena que nosso amigo canino viu quando criança era composta por um grupo de sete cães ("cães como você e eu", escreve o cão narrador) que andavam em fileira, um sobre o outro: ao mesmo tempo mostrando publicamente suas partes íntimas e produzindo uma música mis- 
teriosa, atraente e angustiante. Muito poderia escrever sobre essa música, mas aqui não tenho espaço. Fiquemos com essa imagem do quadrúpede que passa a ostentar seu sexo mas sem se envergonhar dele. Ora, a narrativa que Freud fez no seu "O mal-estar na cultura" é justamente aquela do homem como um ser que ao se tornar bípede teve que recalcar seus instintos - inclusive os sexuais, fortemente ligados ao olfato. A libido recalcada pôde ser canalizada para a cultura. O homem abandona a animalidade ao passar a se envergonhar de seus órgãos sexuais, agora expostos. Esses cães que traumatizam nosso narrador ostentam esse sexo sem pudor. (Eu mesmo, como os senhores podem ler em meu relatório, exponho meu sexo à minha macaca apenas entre quatro paredes. Sou um ser cultural: ein Kulturmensch.) Freud também posteriormente escreveu belas palavras sobre a sexualidade canina e o relacionamento desses animais com suas fezes que nos choca, apesar de ainda tratá-los como nossos melhores amigos.

Muito poderia escrever ainda sobre a relação desses animais com a tradição da fábula, de Esopo a Perrault e Orwell e também sobre outros animais kafkianos. Sua "Josefina, a cantora, ou O povo dos camundongos" é primoroso também. Novamente música, judeidade e sexualidade se misturam aí de um modo bem original. Já o conhecidíssimo $A$ metamorfose se abre com uma frase que resume boa parte da história cultural da primeira metade do século XX: "Als Gregor Samsa eines Morgens aus unruhigen Träumen erwachte, fand er sich in seinem Bett zu einem ungeheueren Ungeziefer verwandelt." Vemos aqui que o prefixo negativo un é a marca desse novo homem que se vê sem proteção (jogado no mal-estar, unbehagen) e às voltas com a culpa, a vergonha e com uma casa - a família - em ruínas. Onde está a família em Kafka? Justamente em torno desse grande inseto e apenas ali. Ele é o sinistro, Unheimlich, aparição daquilo que "deveria permanecer em segredo, escondido e que se manifestou". O prefixo "un" que marca esses termos ("unbehagen", "ungeheuer", "Unheimlich”, "Unbewußten”: mal-estar, monstruoso, sinistro, inconsciente) encontra-se também no centro de uma estética que busca apresentar o "puramente inumano". Kafka foi um dos grandes dessa tradição estética que ele soube remodelar a sua maneira.

Como escreveu o cão investigador que eu cito pela última vez: "Não há aqui nada que compreender, são coisas óbvias e naturais."
(“Quando Gregor Samsa uma manhã despertou de sonhos intranquilos, encontrou-se em sua cama metamorfoseado em um inseto monstruoso.") 
- (BURKE, Edmund. A Philosophical Enquiry into the Origins of our Ideas of the Sublime and Beautiful. Oxford, N. York: Oxford U. Press, 1990: 78. BURKE, Edmund. Uma investigação filosófica sobre a origem de nossas ideias do sublime e do belo. Campinas: Papirus/ UNICAMP, 1993: 92.)

-(BURKE, 1990: 79; BURKE, 1993: 94.)
Queridos colegas, espero que não se ofendam se um velho macaco manco se dirige a vocês como se fosse um par. Mas é que me senti feliz e tocado por ser honrado com a oportunidade de deitar estas palavras para vocês.

\section{Ato}

As matrizes do abjeto: o homem-macaco. Estações de um tema ${ }^{1}$

Edmund Burke, no parágrafo de seu tratado sobre o belo e o sublime de 1757 dedicado ao "Olfato e paladar, amargores e mal cheiro", observa que "nenhum odor ou gosto pode produzir um sentimento de admiração [a grand sensation], com exceção de amargores muito acentuados e maus cheiros intoleráveis." (Burke 1990: 78; Burke 1993: 92) Quando eles são extremamente fortes e "diretamente apoiados no sensório [lean directly upon the sensory]" provocam apenas dor, sem deleite (delight), porém, quando estas sensações são "moderadas, como em uma descrição ou numa narração, tornam-se fontes tão naturais do sublime quanto qualquer outra e estão fundadas no mesmo princípio que o de uma dor moderada." ${ }^{*}$ Ou seja, a participação ou não do olfato (a saber, de cheiros intoleráveis) e do paladar (ou seja, de amargores acentuados) na sensação de sublime depende de um delicado jogo de equilíbrio: eles devem aparecer sob uma forma intensa, mas nunca tão intensa a ponto de serem apenas dor, sem dar espaço para o deleite. O modo de atenuar seu efeito - e toda a questão da teoria do sublime é uma questão de análise do efeito - é a passagem pela narrativa, ou seja, pela via mais racional da verbalização. Apenas assim, respeitando-se a dose correta do amargor e do mal cheiro, pode-se, para Burke, ainda sustentar-se "com dignidade", ou seja, manter-se dentro da esfera do sublime. Para ele, vale lembrar, "a ideia de sublime pertence à autopreservação" e "sua afecção mais forte é o sofrimento". * O parágrafo sobre o odor e o paladar fecha-se aludindo à possibilidade de se incorrer no vitium do exagero nestes pontos. Seus exemplos vêm aqui do campo animal e são es-

\footnotetext{
${ }^{1}$ Este segundo ato foi publicado em uma versão maior como: "As matrizes do abjeto: o homem-macaco. Estaçóes de um tema”. In: DIAS, Ângela Maria e GLANADEL, Paula (orgs.). Valores do abjeto. Niterói: Editora da UFF, 2009: 27-38. ISBN: 8522804893. Republicado in: COUTINHO, Eduardo e COCO, Pina (orgs.). Crossing and contaminations: Studies in Comparative Literature. Rio de Janeiro: Aeroplano, 2009: 201-10.
} 
senciais para o que se segue: "As coisas terríveis [Things which are terrible] são sempre grandiosas [great]; contudo, quando possuem qualidades desagradáveis, assim como quando possuem realmente algum grau de periculosidade, embora de um tipo facilmente superado, são apenas detestáveis [odious], como por exemplo sapos e aranhas." Com este limite, Burke estabelece também uma fronteira entre o sublime e aquilo que se tornou conhecido como abjeto no final do século XX. O sublime ainda era pensado por ele e por seus sucessores (Mendelssohn, Kant, Schiller) na chave do decoro retórico. O que ele denomina de "detestável" deve ser aproximado do abjeto. Ambos os conceitos implicam uma recusa, uma negação. Lembremos que o abjeto, como define o Houaiss, é o "que é desprezível, baixo, ignóbil” e deriva do latim abjectus, “atirado por terra, derribado, desprezível, vil, [...] rasteiro, baixo, abatido", sendo que o particípio passado do verbo abjecere significa "lançar, atirar, derribar, deitar abaixo, desprezar, rejeitar". A questão é que Burke e os teóricos do sublime mantêm o odious/detestável e aquilo que Mendelssohn e Kant denominaram de Ekelhaft, o asqueroso, fora do campo das representações artísticas."

Gostaria de refletir sobre um possível paralelo que proponho entre a construção no campo estético (tanto das obras como na teoria) deste conceito de abjeto (em seu parentesco com o sublime, o odious e o asqueroso) e, por outro lado, as descobertas científicas que se deram ao longo do século XIX. É importante apontar para a simultaneidade do que pode ser descrito como o brotamento do veio subterrâneo do abjeto, que passou cada vez mais a se manifestar nas obras de arte e, por outro lado, a radical mudança na visão de homem que a teoria darwiniana da evolução das espécies representou. Minha tese é que existe uma relação mais do que meramente histórica entre o fato de Darwin e a ciência terem revelado o ser animal na nossa origem ao mesmo tempo em que a estética clássica sucumbiu sob o peso das apresentaçôes abjetas.

O abjeto, aquilo que é recusado, ejetado, vomitado, é, para Kristeva, um "objeto" originário, é o "refoulement originaire", "recalcamento originário". Ele nos defronta, ela escreveu em seu livro de 1980, "com estes estados frágeis onde o homem erra nos territórios do animal". 'Se o sublime é todo derivado da autopreservação, o abjeto ilumina nosso ser fragmentado: ele também é originário e também dele nasce a nossa vida, mas o foco agora é lançado da "outra borda", ou seja, da margem sem linha do "sujei-
'(BURKE, 1990: 79; BURKE, 1993: 93.)

- (SELIGMANN-SILVA, Márcio. O local da diferença. Ensaios sobre memória, arte, literatura e tradução. São Paulo: Editora 34, 2005: 31-56.)

- (KRISTEVA, Julia. Pouvoirs de l'horreur. Essai sur l'Abjection, Paris: Seuil, 1980: 20.) 
(Cf. MENNINGHAUS, Winfried. Ekel. Theorie und Geschichte einer starken Empfindung. Frankfurt a.M.: Suhrkamp, 1999: 485 ss.) to" pré-subjetivo, quando o mundo ainda não era mundo. Se no sublime existe deleite, no abjeto existe gozo, jouissance, um prazer ambíguo derivado da catársis do Outro, que traça ao mesmo tempo a catastrófica topografia do nosso ser. ${ }^{*} \mathrm{Ou}$ seja, o abjeto é pensado a partir de Kristeva como algo que nos remete ao momento ritual de nossa cultura, ele obriga o simbólico a um ato regressivo para garantir a si mesmo, já que este mundo está desde sempre ameaçado de romper sob a força de uma massa abjeta originária que insiste em vir à tona.

Neste sentido vale à pena antes de falar da questão animal, recordar alguns outros componentes desta constelação conceitual que tem hoje em dia o abjeto como sua estrela mais visível. Nesta imagem estelar vê-se também de modo claro - e como que concorrendo com a ambígua luminosidade do abjeto - o conceito de "informe" de Bataille. Rosalind Krauss (re)lançou este conceito concorrente em grande estilo e a partir da exposição de 1996 no Centre Georges Pompidou e do seu catálogo editado junto com Yve Alain Bois (l'informe. Mode d'emploi) ${ }^{2}$ pode-se dizer que estes dois conceitos têm participado em iguais doses no campo teórico e prático do sublime contemporâneo. As contribuiçóes de Bataille à revista Documents dos anos 1929 e seguinte constituem um verdadeiro campo de batalha contra os ideais de beleza clássicos e a idealização da arte. ${ }^{*} \mathrm{O}$ artigo Bouche, por exemplo, escancara em uma foto uma enorme boca aberta: um verdadeiro ataque direto à máxima de Lessing, que no seu Laocoonte, de 1766, reivindicara uma estética da contenção e do ocultamento dos orifícios corporais como sendo um dos pilares das artes plásticas. A anatomia cômica dos macacos também entra em cena nesta campanha artística. Ao invés do modelo solar Apolíneo, que tinha uma visualidade ideal no seu centro, Bataille propõe L'anus solaire já em 1927, como que revelando o elemento abjeto da imagem solar, ou transformando o culto do belo em culto escatológico. Este programa estético desdobra-se ainda em um culto da sexualidade violenta e numa interpretação sacrificial da arte. "Como Nietzsche, Bataille diagnosti-

\footnotetext{
${ }^{2}$ Esta exposição de Paris tinha quatro pontos cardinais que a organizaram: materialismo de base, horizontalidade, "pulse" e entropia. (NELSON, Robert S. e SHIFF, Richard (orgs.). Critical Terms for Art History. Chicago, London: The University of Chicago Press, segunda edição, 2003: 291). Ela foi um contraponto à exposição de 1993 do Whitney Museum of Modern Art Abject Art.
} 
ca nos seus contemporâneos um auto-asco dos instintos de animal de rapina que tem uma origem na fraqueza." Para ele perdemos nossa "crueldade inocente": deveríamos libertar o animal acorrentado dentro de nós. Depois de Sade, já Baudelaire associara tortura e volúpia. No seu Mon coeur mis à nu este escreveu: "Crueldade e volúpia, sensações idênticas, como o extremo calor e o extremo frio."* E no seu Les Paradis artificiels ele anotou: "Pois, assim como de uma droga terrível, o ser humano goza deste privilégio de poder extrair novos e sutis prazeres mesmo da dor, da catástrofe e da fatalidade."* Com Bataille este movimento de entrega à crueldade e a uma estética do sangue e da dor se radicaliza: a tragédia deste modo é reatualizada no seu elemento dionisíaco e enquanto capacidade de se extrair prazer do medo. O belo só encontra lugar aqui enquanto algo a ser sacrificado: como espaço para dessacralização e fonte de gozo na sua desfiguração e "defloração". Na estrutura do sagrado, com Durkheim e M. Mauss, Bataille vislumbra a própria necessidade do sacrilégio. Mas mesmo tendo escrito sobre a "abjection humaine" não podemos confundir a antiestética de Bataille com o conceito de abjeção de Kristeva. Em Bataille não vislumbramos, como Menninghaus notou, nem uma teoria da economia das pulsões, nem as dimensões psico-históricas e não objetais, tão centrais para Kristeva e sua noção de abjeção originária da mãe.* Além disso o erotismo em Bataille está calcado no desejo masculino, enquanto Kristeva fala da "economia biopulsional" de um corpo materno pré-objetal e de um tornar-se objeto.

Bataille é importante, enquanto uma figura central da revolta contra o modelo clássico, e como continuador da reestruturação do estético a partir daquilo que Adorno definiu como "desencadeamento do elementar". Este processo, Adorno escreveu ainda, estaria vinculado à "autoconsciência" de nosso "ser natural". Para este filósofo, a arte passou a ser comandada a partir sobretudo do romantismo por uma dialética entre o "espiritual" e o "elementar" (ou "repelente", "desagradável”: em uma palavra, o nosso "ser natureza" sempre recalcado ou o nosso ser "apenas um animal" que Schiller tentara descartar da literatura).

Esta passagem entre a forma humana e a animal era um topos antigo, mas que estava em moda muito antes das descobertas de Darwin. Ao longo do século XVIII havia um conflito entre os adeptos da teoria da "grande cadeia dos seres", que acreditavam existir uma continuidade entre o mundo mineral, vegetal e ani-

- (MENNINGHAUS. op. cit.: 523.)

- (ADORNO, Theodor. Teoria Estética. Trad. Artur Mourão. Lisboa: Edições 70, 1982: 222; ADORNO, Theodor. Ästhetische Theorie. org. por Rolf Tiedemann e Gretel Adorno. Frankfurt/M.: Suhrkamp, 1970, 292.) 
(Cf. BINDMAN, David. Ape to Apollo. Aesthetics and the Idea of Race in the $18^{\text {th }}$ Century. London: Reaktion Books, 2002: 70.)

(Cf. Ibidem: 152.$)$

" Variétés dans l'espèce humaine, apud BINDMAN. op. cit.: 234.) mal, indo das espécies mais simples às mais complexas e, por outro lado, aqueles que se empenhavam em distinguir de modo claro o homem do resto da criação. Esta última postura era, como é evidente, muito mais compatível com os dogmas da igreja, que autores como Herder e Kant ainda tentaram salvar nas suas incursões na antropologia. Mas a teoria da grande cadeia dos seres permitia, por exemplo, aproximar os negros dos animais, sobretudo dos macacos. Em Daniel Defoe, por exemplo, vemos a descrição dos selvagens como marcada pela ambiguidade: eles oscilariam entre os pólos da docilidade (Sexta-Feira) e da ferocidade (demais membros da tribo de Sexta-Feira, que são canibais). Deste modo o autor aproxima os "selvagens" dos animais, que são ora dóceis (ou seja, domesticáveis), ora pertencentes a uma natureza descontrolada, externa à civilização. Também o filósofo David Hume aproximava os negros dos animais.

Edward Long, no seu History of Jamaica foi um dos maiores formuladores da animalidade dos negros, derivando desta tese a justificativa da escravidão. Ele afirmava que negros na África tinham relações sexuais com símios. Contra a concepção cristã da monogênese, ele propôs a poligênese, já que para ele brancos e negros constituíam duas espécies distintas. Com Hume, ele via os negros desprovidos de gênio, de ciência e de capacidade para o progresso. Pensando na grande cadeia dos seres, ele aproxima os negros dos primatas. Buffon, antes dele, ao relacionar as diferentes raças aos climas e sua influência, já adiantara ideias próximas às de Long. É importante observar como estas teorias todas tinham um forte teor estético e eurocêntrico: Buffon condena a "feiúra" dos tipos não-europeus e os estigmatiza como sendo degenerados. Analisando o aspecto exterior dos lapóes, por exemplo, ele escreveu:

eles são todos igualmente grosseiros, supersticiosos, estúpidos [...] a maior parte é idólatra, [...]; eles são mais grosseiros que os selvagens, sem coragem, sem respeito por si mesmo, sem pudor; este povo abjeto [abject] não possui hábitos senão o suficiente para serem desprezados.

Mas em Buffon, diferentemente de Long, não há lugar para a tese da poligenia. Mas a concepção "científica" de que pode existir um "povo abjeto" não deixa de ser importante e possui, como se sabe, uma triste carreira, até nossos dias. 
Já a teoria da evolução das espécies entronizou a noção de que o homem é parte da cadeia animal. Com suas análises empíricas Darwin derrubou (ou ao menos tentou superar) os adeptos das teorias pré-científicas creacionistas. É interessante lembrar de algumas passagens da sua teoria, sobretudo do seu livro $A$ expressão das emoçôes no homem e nos animais, de 1872 , peça fundamental na divulgação de sua teoria da evolução das espécies e da seleção natural. Nesta obra ele realiza um trabalho de comparação entre a expressão das emoções no homem e em diversos animais. Ele mobilizou um impressionante exército de correspondentes, espalhados pelos quatro cantos do mundo, que lhe enviaram detalhadas descrições das reações e expressōes (faciais, mas gestos também) das populações autóctones. A ideia era a de comprovar a unidade da espécie humana, na mesma medida em que ela era vinculada aos demais animais. Tendo em vista captar algo como a "essência" da humanidade (do homem independentemente da sua educação), dado fundamental para a teoria que ele queria defender, Darwin recorre a descrições de reações e expressões de "loucos", de crianças, às famosas fotografias de faces com músculos galvanizados de autoria de Duchenne, a obras da história da arte e, por fim, como mencionado, à comparação de "diferentes raças humanas". Recordemos desta passagem ilustrativa deste projeto:

Nos humanos, algumas expressões, como o arrepiar dos cabelos sob a influência de terror extremo, ou mostrar os dentes quando furioso ao extremo, dificilmente podem ser compreendidas sem a crença de que o homem existiu um dia numa forma mais inferior e animalesca. A partilha de certas expressões por espécies diferentes ainda que próximas, como na contração dos mesmos músculos faciais durante o riso pelo homem e por vários grupos de macacos, torna-se mais inteligível se acreditarmos que ambos descendem de um ancestral comum. Aquele que admitir que, no geral, a estrutura e os hábitos de todos os animais evoluíram gradualmente, abordará toda a questão da Expressão a partir de uma perspectiva nova e interessante.

Em Darwin encontramos, portanto, esta clara proposição da existência de algo como "o animal dentro de nós”. Por outro lado, ao descrever as reações e expressões humanas e animais, ele toca no nosso tema de modo a lembrar o que vimos com Burke. No item dedicado à expressão do disgust, nojo, reencontramos a questão do abjeto. "O termo disgust ("nojo"), na sua acepção mais simples, significa algo desagradável ao paladar.” Um nativo da Terra do Fogo, narra Darwin, ao tocar a carne fria que o cientista comia demons-
- (DARWIN, Charles. A expressão das emoções no homem e nos animais. Trad. Leon Garcia. São Paulo, Companhia das Letras, 2000: 24)

"(Ibidem: 22.)

(lbidem: 241.) 
trou "enorme nojo pela sua consistência mole". E Darwin continua: "enquanto eu senti um profundo nojo em ver minha comida ser tocada por um nativo nu, apesar de suas mãos não parecerem sujas." Darwin não analisa por que ele teve nojo deste nativo, mas para ele deveria ser natural enojar-se com este toque de "um nativo nu", mesmo que ele estivesse com as mão limpas: não se tratava de um questão de higiene, o nojo aqui indica a abjeção ao "outro", ao nativo, ao nu. Por outro lado, sua reflexão sobre por que temos nojo de restos e comida na barba de um homem, não deixa de revelar um insight quase psicanalítico: sempre que vemos comida associamos isto com "a ideia de comê-la". Mas Darwin infelizmente também neste ponto não completa a explicação. Decerto a ideia de aproximar a boca da barba do homem seria o que desencadeia o nojo. A abjeção também transita nas bordas dos gêneros e dos desejos denegados. A expressão do nojo, para Darwin, seria uma espécie de derivado dos atos de cuspir e de vomitar. Ele propõe que nossos ancestrais deveriam ter a capacidade de regurgitar voluntariamente uma comida que não lhes fizesse bem. Macacos teriam este hábito. O círculo se fecha: da abjeção ao outro, ao macaco que abjeta, a própria abjeção torna-se uma prova de nossa animalidade e, poderíamos pensar como veremos com Kafka, uma comprovação da "hominidade" do macaco.

Obras como o Frankenstein de Mary Shelley, de 1817, e os contos de Hoffman com suas pessoas autômatos também discutiam os limites do humano e procuravam dar forma a uma nova sensibilidade. Dr. Jeckyl and Mr. Hyde, de 1886, foi composto após as publicações de Darwin. Nestas obras não se trata mais do cômico (como em Hogarth) nem da análise do caráter das fisionomias (como em Lavater), mas antes de se incorporar o elemento terrorífico, Unheimlich, diria Freud, de nossa "origem", seja ela interpretada segundo a teoria freudiana do recalque, seja pensando-se na teoria do abjeto como constitutivo e negativo do simbólico.

Para se aproximar do sentimento de asco expressado por exemplo por Ottilie - personagem de Goethe de As afinidades eletivas - com relação às nossas afinidades eletivas com nossos parentes primatas, vale a pena recordar as palavras utilizadas por Freud para determinar a origem de nossa capacidade de juízo no seu texto Die Verneinung (A denegação, 1925). Devemos lembrar que a denegação é um caminho aberto para nosso diálogo com o recalcado. No texto de Freud a faculdade de juízo é derivada de um "có- 
digo elementar do Ego-Prazer que consiste na diferenciação binária entre 'introduzir em mim' e 'eliminar de si'”. . Freud escreve que isto se expressa "Na língua das pulsóes [Triebregungen] orais mais antigas: eu quero comer isso ou quero cuspir, e traduzindo de modo aberto [in weitergehender Übertragung]: eu quero introduzir isto em mim e retirar aquilo de mim. Ou seja: deve estar em mim ou fora de mim. O Ego-Prazer originário quer [...] introjetar tudo que é bom, e expulsar tudo que é ruim. "* Não precisamos realizar nenhum grande salto para aproximarmos esta ideia da noção de abjeto, mesmo que não exista de fato uma correspondência estrita entre este conceito de Kristeva e esta teoria do juízo. Sem contar que para Freud o asco justamente desperta sentimentos arcaicos e recalcados do tipo polimorfo-perverso. O prazer com o excremento para ele seria uma tal herança arcaica e "uma prática infantil evidente; apenas no campo do recalcamento cultural e dos limites do asco a fixação extemporânea nele tende para o precipício das perversões". * Não podemos esquecer que para Freud o processo de aculturação se confunde com o de hominização e passa pelo recalque de nossos instintos e predileçôes animais, que são enviados para o fundo do nosso ser. Como lemos em $O$ mal-estar na Cultura, a passagem do modo de andar quadrúpede para o bípede determinou uma série de repressões com relação ao olfato e seu papel na excitação e relacionamento humano e, por outro lado, o aumento do papel da visualidade. "Um fator social está também, inequivocamente," escreve Freud, "presente na tendência cultural para a limpeza, que recebeu, expost facto, justificativa em consideraçôes higiênicas, embora tenha se manifestado antes da descoberta destas. $\mathrm{O}$ incentivo à limpeza origina-se num impulso a livrar-se das excreções, que se tornaram desagradáveis à percepção dos sentidos. Sabemos que, no quarto das crianças, as coisas são diferentes."* Para Freud, utilizamos o nome de nosso melhor amigo, o cão, como injúria, justamente porque ele tem o olfato como sentido dominante, não sente repulsa com relação a seus excrementos, nem se envergonha de suas funções sexuais.

Não por acaso o conhecido texto de Kafka, "Um relatório para uma Academia”, que tem como protagonista um macaco hominizado que fala diante de uma academia, descrevendo a sua aventura de aculturação, tem como pedra de toque desta aventura o dia em que ele aprendeu a cuspir. $\mathrm{O}$ sábio macaco fora capturado quando atingido por dois disparos: um teria penetrado na maçã de sua

(FREUD, Sigmund. O mal-
-estar na cultura. Tradução
de Renato Zwick. Revisão
e introdução de M. Selig-
L\&M, 2010: 54.)


(1) Plegre:

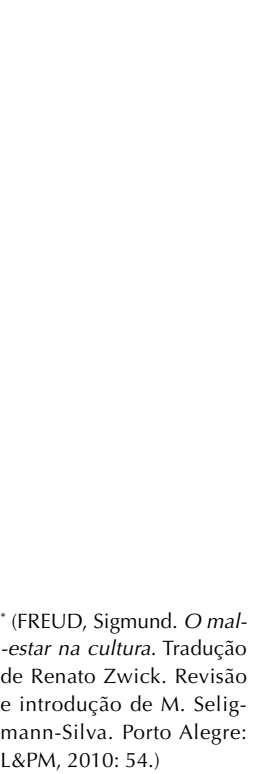

e introdução de M. Selig-
mann-Silva. Porto Alegre:
L\&PM, 2010: 54.)
-estar na cultura. Tradução
(FREUD, Sigmund. O mal-
denato Zwick. Revisão
(a)

e introdução de M. Selig-
mann-Silva. Porto Alegre:
L\&PM, 2010: 54.)
-estar na cultura. Tradução
(FREUD, Sigmund. O mal-
denato Zwick. Revisão

e introdução de M. Selig-
mann-Silva. Porto Alegre:
L\&PM, 2010: 54.)
-estar na cultura. Tradução
(FREUD, Sigmund. O mal-
denato Zwick. Revisão
(a)

e introdução de M. Selig-
mann-Silva. Porto Alegre:
L\&PM, 2010: 54.)
-estar na cultura. Tradução
de Renato Zwick. Revisão
(FRED, Sigmund. O mal-

* (Apud MENNINGHAUS. op. cit.: 519.)

- (Apud MENNINGHAUS. op. cit.: 533.)

* (MENNINGHAUS. op. cit.: 519.)

LePM, $2010: 54$. 
" (KAFKA, Franz. Um médico rural. Obras Completas. Tradução de Modesto Carone. São Paulo: Companhia das Letras, 1999: 70.) cara - quantas maçãs no processo cultural e em nossas quedas... - e o outro disparo pegou no seu traseiro, que devia estar exposto demais. Nosso amigo palestrante ironiza ainda a ideia de liberdade em seu relatório: como Freud, ele sabe que só nos tornamos homem graças à nossa capacidade de moldar nossos corpos às grades de uma prisão, como ele mesmo o fez quando foi capturado. E mais, o macaco tornou-se homem, como não poderia deixar de ser, como todos nós: ou seja, imitando os outros homens. Seu primeiro ato humano, portanto, foi cuspir. Abjetando seu cuspe ele deu a entender que era inteligente. Parafraseando Borges, podemos escrever: Darwin foi um grande leitor de Kafka. Depois veio o cachimbo e em seguida a aguardente. Afinal Adão e Eva também começaram tudo com um pecadinho. Já em Hamburgo a natureza de macaco escapou dele rapidamente de modo que seu "primeiro professor quase se tornou ele próprio um símio".* Nesta narrativa de Kafka o nosso ser animal abjeto toma a palavra e reivindica a literatura como seu reino absoluto. $\mathrm{O}$ macaco-homem, ou homem-macaco dá voz a este animal que se desencadeou de dentro de nós. Ele nos remete a uma origem filo e ontogenética com uma ironia que apenas Kafka conseguiu dominar totalmente.

\section{Fechando o pano ${ }^{3}$}

Essa questão da nossa animalidade deve ser contextualizada no campo de pesquisas sobre as tensōes entre a zoé e a bios, ou seja, a nossa vida animal e a vida organizada. Como H.Arendt, Foucault e mais recentemente Agamben o mostraram, nossa cultura ocidental tendeu a uma politização da zoé. Com Freud, como fica claro no seu ensaio $O$ mal-estar na cultura, nosso processo de aculturação é um largo processo de afastamento, recalcamento e de despedida de nosso corpo. Nossa "vida" torna-se algo que tem que ser administrado e enfrentado com técnicas que visam reimplantar o princípio de prazer, ali onde a sociedade quer a todo custo impor o princípio da vida em comum e o abrir mão da felicidade em favor dessa comunhão. ${ }^{4}$ Pode-se falar de uma "dialética da compai-

\footnotetext{
${ }^{3}$ Estas observações finais retomam com poucas mudanças algumas páginas do meu ensaio Para uma crítica da compaixão. São Paulo: Lumme Editor, 2009.

4 "No processo de desenvolvimento do indivíduo, a meta principal é o programa do princípio do prazer, que consiste em obter satisfações que proporcionem felicidade [...]. É diferente no caso do processo cultural; nele, a meta da produção de uma unidade composta de indivíduos humanos é, de longe, o principal; a
} 
xão”, na medida em que a sociedade mais e mais amplia seu círculo de culturas, etnias e de populaçôes humanas, mas também de animais e de vegetais que devem ser incluídos e unificados neste grande plano de construção de uma unidade da vida. Aqui, a proteção não se deixa distinguir do controle.

J.M. Coetzee é um dos escritores da atualidade que mais e melhor tem refletido sobre estas questões. Nele o que Agamben denomina de biopolítica surge tanto na reflexão sobre a gestão da vida e da morte com relação aos que são expulsos como "resto" da sociedade, como também em suas incursões literário-filosóficas no campo do estudo das fronteiras entre o ser humano e o animal. Em seu Vida e época de Michael K, por exemplo, ele narra a história de um negro que se encontra sem lugar na sociedade sul-africana onde o apartheid está desmoronando. Mas Michael K não representa apenas o negro sul-africano, ele pode ser lido como um representante dos excluídos que ficam a cargo do assistencialismo com sua dupla face de caridade e de controle. No final do livro, totalmente sem-lugar, ele pensa: "Virei um objeto de caridade [...]. Talvez a verdade seja que basta estar fora dos campos, fora de todos os campos ao mesmo tempo. Talvez isso já seja uma conquista, por enquanto. Quanta gente sobrou que não está nem trancada, nem montando guarda no portão? Eu escapei dos campos; talvez, se eu ficar na minha, escape da caridade também." Já em $A$ vida dos animais, Coetzee, por meio de sua alter-ego Elisabeth Costello - uma escritora australiana de sucesso, vegana e abolicionista dos animais - apresenta diversas passagens sobre a compaixão e a simpatia. Para Costello, diferentemente do que ocorrera com Buffon ${ }^{5}$

meta de tornar-se feliz certamente ainda continua de pé, mas é empurrada para o segundo plano, e quase se tem a impressão de que a criação de uma grande comunidade humana seria mais bem-sucedida caso não fosse preciso se preocupar com a felicidade do indivíduo.” (FREUD. op. cit.: 174s.)

${ }^{5} \mathrm{O}$ que Buffon escreveu sobre a compaixão deixa claro o seu modo de funcionamento que para este naturalista era mais corpóreo e "animal" do que cultural: "Existe, portanto, uma espécie de insensibilidade cruel em sacrificar sem necessidade, sobretudo aqueles [animais] que se aproximam de nós, que vivem conosco e cujo sentimento reflete-se para nós, destacando-se pelos signos da dor; pois aqueles cuja natureza é diferente da nossa, praticamente não podem nos afetar. A piedade natural funda-se nas relações que nós temos com o objeto que sofre; ela é tanto mais viva quanto maiores forem a semelhança e a conformidade natural; sofremos ao ver sofrer nosso igual. [La pitié naturelle est fondée sur les rapports que nous avons avec l'objet qui souffre; elle est d'autant plus vive que la ressemblance, la conformité de nature est plus grande; on souffre en voyant souffrir son semblable.] Compaixão; esta palavra exprime suficientemente que se trata de um sofrimento,
"(COETZEE, J.M. Vida e época de Michael K. Trad. José

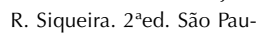
lo: Companhia das Letras, 2003: 208s.) 
· (COETZEE, J.M. A vida dos animais. Trad. José R. Siqueira. São Paulo: Companhia das Letras, 2002: 43.)

•(Ibidem: 70.)

·(Kafka, 1999: 72.) e mais próxima de Bentham, ${ }^{6}$ podemos nos identificar até com uma ostra: "não há limites para nossa capacidade de perceber pelo pensamento a dor de outrem. Não há limites para a imaginação simpatizante."* Ela compara o assassinato cotidiano de milhões de animais a um Holocausto sem fim. Para ela existiria um estado de exceção na nossa relação com animais, uma situação de guerra, na qual "não existe lei". . Costello acredita que a compaixão para com os animais é recente e antes de mais nada anglo-saxã. Ou seja, pode ser lida também como mais um passo no colonialismo congênito da Aufklärung (o Esclarecimento). Impossível reproduzir aqui as sutilezas deste texto polifônico de Coetzee, que ao mesmo tempo que enuncia e defende com fortes argumentos as teses veganas, as ironiza e critica. Mas o ponto do autor é justamente mostrar as aporias com as quais nos defrontamos quando passamos a pensar a política do ponto de vista da alimentação e da compaixão. O grande trunfo da literatura (e do ensaísmo sério) é não se submeter a soluções simplistas fáceis.

Fiz aqui tão somente um pequeno relatório: "aos senhores, eminentes membros da Academia, só apresentei um relatório”.

\section{Márcio Seligmann-Silva (IEL-UNICAMP)}

É doutor pela Universidade Livre de Berlim, pós-doutor por Yale e professor livre-docente de Teoria Literária na UNICAMP. É autor de Ler o livro do mundo (Iluminuras, 1999), Adorno (PubliFolha, 2003), O local da diferença (Editora 34, 2005), Para uma cri-

de uma paixão que nós compartimos; no entanto é menos o homem que sofre, do que sua própria natureza que padece, que se revolta maquinalmente e coloca-se ela mesma em uníssono com a dor. A alma tem menos a ver do que o corpo neste sentimento de piedade natural e os animais, assim como o homem, são suscetíveis a ele; o grito de dor os comove, eles correm para socorrer; eles retrocedem diante da visão de um cadáver da sua espécie. Assim, o horror e a piedade são menos paixões da alma e mais afecçóes naturais [des affections naturelles], que dependem da sensibilidade do corpo e da semelhança de conformação; este sentimento deve, portanto, diminuir na medida em que as naturezas se distanciam. Um cão que nós batemos, um carneiro que nós degolamos, provocam alguma piedade em nós; uma árvore que nós cortamos, uma ostra que nós mordemos, não provocam nenhuma piedade." (BUFFON, Georges-Louis Leclerc. Histoire Naturelle.In: Euvres. Paris: Gallimard, 2007: 748s.) A história do Iluminismo é a da ampliação deste círculo de empatia - que é paralela e não oposta à ampliação da violência.

6 "Chegará um dia quando a humanidade estenderá seu manto sobre tudo que respira. [Il viendra un temps où l'humanité étendra son manteau sur tout ce qui respire.] Começamos a nos enternecer quanto à sorte dos escravos: acabaremos por adoçar aquela dos animais que servem a nossos trabalhos e a nossas necessidades." (BENTHAM, Jeremy. Theory of Legislation [1802]. London: Trübner, 1864: 428s.) 
tica da compaixão (Lumme Editor, 2009) e $A$ atualidade de Walter Benjamin e de Theodor W. Adorno (Editora Civilização Brasileira, 2009); organizou os volumes Leituras de Walter Benjamin: (Annablume/FAPESP, 1999; 2a . edição 2007), História, memória, literatura: o testemunho na era das catástrofes (UNICAMP, 2003) e Palavra e imagem, memória e escritura (Argos, 2006) e coorganizou Catástrofe e representação (Escuta, 2000).

\section{Resumo}

O texto possui três partes. Na primeira o autor assume a identidade do personagem Rotpeter, de Kafka, e escreve sobre a questão dos animais no escritor de Praga. Na segunda parte faz-se uma incursão sobre as origens da questão da animalidade na nossa cultura moderna. Para tanto o autor retoma questóes tratadas desde a fundação da Estética, assim como ilumina o encontro entre a reflexão estética e a ciência (com estaque para Darwin e sua teoria da origem das espécies). Na conclusão o texto mostra como esse debate em torno da questão animal e da "natureza" pode ser pensado no contexto do tema biopolítico da compaixão. Nesse momento retoma-se duas obras de J.M. Coetzee, mostrando em que medida a compaixão e a caridade podem estar na origem de uma simples tutela autoritária do "outro".

\section{Abstract}

The text has three parts. In the first step, the author assumes the identity of the character created by Kafka, Rotpeter, and writes about the question of animality in the works of the writer from Prague. In the second part, there is a discussion about the origins of the topos of animality in the contemporary culture. For that, the author retrieves topics that emerged at the foundation of the Aesthetics, as well as presents the crossings among aesthetics and science (specially the theorem of the origin of the

\section{Résumé}

Le texte comporte trois parties. Dans la première l'auteur assume l'identité du personnage Rotpeter, de Kafka, et écrit sur la question des animaux chez l'écrivain de Prague. Dans la deuxième, on fait une incursion sur les origines de la question de l'animalité dans notre culture moderne. Pour cela l'auteur reprend des questions traitées depuis la fondation de l'Esthétique de la même manière qu'il illumine la rencontre de la réflexion esthétique et de la science (surtout chez Darwin avec sa théorie
Palavras-chave: animalidade; compaixão; abjeto.

Key words: animality; compassion; abjection.

Mots-clés: animalité; compassion; abjection. 
species, by Darwin). In the conclusion, the text shows how this debate about the animal and the "nature" issues can be though in the context of the biopolitical issue of compassion. At this point, the author bases his discussion on two books by J.M. Coetzee, and shows how compassion and charity can be at the origin of an authoritarian tutelage of the "other". de l'origine des espèces) Dans la conclusion le texte montre comment ce débat autour de la question de l'animal et de la "nature" peut être pensé dans le contexte du thème biopolitique de la compassion. On y reprend alors deux œuvres de J. M. Coetzee, faisant voir dans quelle mesure la compassion et la charité peuvent être à l'origine d'une simple tutelle autoritaire de l'“autre". 